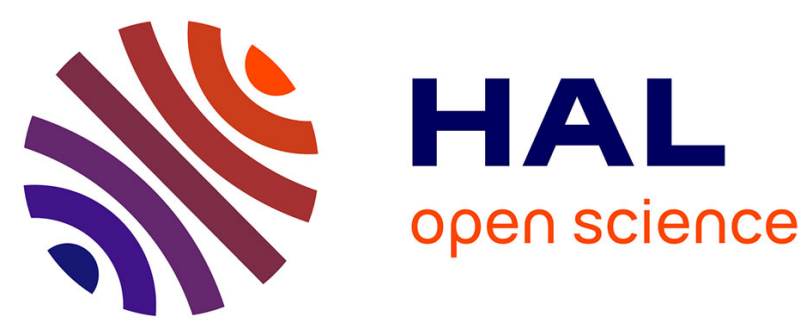

\title{
Evidence for an Association Between Intrahepatic Vascular Changes and the Development of Hepatopulmonary Syndrome
}

Clément Lejealle, Valérie Paradis, Onorina Bruno, Emmanuelle de Raucourt, Claire Francoz, Olivier Soubrane, Didier Lebrec, Pierre Bedossa, Dominique Valla, Hervé Mal, et al.

\section{To cite this version:}

Clément Lejealle, Valérie Paradis, Onorina Bruno, Emmanuelle de Raucourt, Claire Francoz, et al.. Evidence for an Association Between Intrahepatic Vascular Changes and the Development of Hepatopulmonary Syndrome. Chest, 2019, 155, pp.123 - 136. 10.1016/j.chest.2018.09.017 . hal-03486824

\section{HAL Id: hal-03486824 \\ https://hal.science/hal-03486824}

Submitted on 20 Dec 2021

HAL is a multi-disciplinary open access archive for the deposit and dissemination of scientific research documents, whether they are published or not. The documents may come from teaching and research institutions in France or abroad, or from public or private research centers.
L'archive ouverte pluridisciplinaire HAL, est destinée au dépôt et à la diffusion de documents scientifiques de niveau recherche, publiés ou non, émanant des établissements d'enseignement et de recherche français ou étrangers, des laboratoires publics ou privés.

\section{(ㅇ)(1) $\$$}

Distributed under a Creative Commons Attribution - NonCommerciall 4.0 International 
1 Body of manuscript word count: 2645 words, not including the abstract, references,

2 tables, and figure legends

3 Abstract word count: 249 words

Evidence for an association between intrahepatic vascular changes

Running Head: Liver vascular pattern of damage and HPS

9 Clément Lejealle ${ }^{1,5} \mathrm{MD}$, Valérie Paradis ${ }^{2,5,6} \mathrm{MD}, \mathrm{PhD}$, Onorina Bruno ${ }^{3} \mathrm{MD}$, Emmanuelle de

10 Raucourt ${ }^{4} \mathrm{MD}, \mathrm{PhD}$, Claire Francoz ${ }^{1,5} \mathrm{MD}, \mathrm{PhD}$, Olivier Soubrane ${ }^{6,7} \mathrm{MD}, \mathrm{PhD}$, Didier

11 Lebrec $^{1,5,6} \mathrm{MD}, \mathrm{PhD}$, Pierre Bedossa ${ }^{2,5,6} \mathrm{MD}$, PhD, Dominique Valla ${ }^{1,5,6} \mathrm{MD}, \mathrm{PhD}$, Hervé

1 Service d'Hépatologie, DHU Unity, Hôpital Beaujon, Assistance Publique-Hôpitaux de 16 Paris, Clichy, France

${ }^{2}$ Service d'Anatomie Pathologique, Hôpital Beaujon, Assistance Publique-Hôpitaux de Paris, 18 Clichy, France

$19{ }^{3}$ Service d'imagerie, Hôpital Beaujon, Assistance Publique-Hôpitaux de Paris, Clichy, France

$20{ }^{4}$ Service d'Hématologie-Biologique, Hôpital Beaujon, Assistance Publique-Hôpitaux de

21 Paris, Clichy, France

$22{ }^{5}$ INSERM, UMR-1149, Centre de Recherche sur l'inflammation, Paris-Clichy, France

$23{ }^{6}$ Université Denis Diderot-Paris 7, Sorbonne Paris Cité, 75018 Paris, France

$24{ }^{7}$ Service de Chirurgie hépato-biliaire et Transplantation Hépatique, Hôpital Beaujon, 25 Assistance Publique-Hôpitaux de Paris, Clichy, France 
$1{ }^{8}$ Service de Pneumologie B et Transplantation Pulmonaire, Hôpital Bichat, Assistance

2 Publique-Hôpitaux de Paris, Paris, France

$3{ }^{8}$ INSERM, UMR-970, Paris Cardiovascular Research Center - PARCC, Paris, France

4

5

6 Corresponding author:

7 Prof. Pierre-Emmanuel Rautou

8 Service d'Hépatologie,

9 Hôpital Beaujon,

10100 boulevard du Général Leclerc,

1192110 Clichy, France

12

13 Disclosures: none

14

Financial support statement: This work was supported by the Agence Nationale pour la Recherche (ANR-14-CE12-0011 and ANR-14-CE35-0022) and by the Association Française pour l'Etude du foie (AFEF 2009).

18

Prior abstract presentation: This article has been presented in oral communication at the Liver Meeting 2016 - American Association for the Study of Liver Diseases, 67th Annual

21 Meeting (November 11-15, 2016 - Boston, Massachusetts, USA)

Figures: 3

Tables: 4 


\section{Abbreviations}

2 HPS: hepatopulmonary syndrome

3 MDCT: multidetector computed tomography

4 MELD: model for end-stage liver disease

$5 \quad \mathrm{PaO} 2$ : partial pressure of arterial oxygen

6

7 


\section{ABSTRACT}

2 Backgrounds: Hepatopulmonary syndrome (HPS) is characterized by an arterial

3 oxygenation defect - defined by an increased alveolar-arterial oxygen gradient - induced by

4 pulmonay vascular dilatations in the context of liver disease. The pathogenesis of HPS is

5 poorly understood. Morphological changes associated with HPS are unknown.

6 This study aimed at describing imaging and pathology changes associated with HPS.

7 Methods: We performed a case-control study in candidates for transplant with suspicion of 8 cirrhosis. Each patient with HPS $\left(\mathrm{PaO}_{2} \leq 70 \mathrm{~mm} \mathrm{Hg}\right)$ was matched to 3 controls for age, 9 cause and liver disease severity. Pretransplant thoracic and abdominal imaging and explanted livers were reviewed.

Results: CT-scans and Doppler ultrasounds from 21 patients with HPS were compared with

12 those from 63 controls. HPS was associated with a 2 to 3 -fold higher prevalence of 13 obstructed intrahepatic portal branches, of slowed or hepatofugal portal blood flow, and of 14 large abdominal portosystemic shunts. Hepatic artery diameter was also larger in patients with HPS. Explanted livers from 19 patients with HPS were compared with those from 57 controls. HPS was associated with a 4-fold higher prevalence of portal venules thrombosis and a nine fold higher prevalence of extensive vascular proliferation within fibrous septa. Obstruction of centrilobular veins, sinusoidal dilatation and liver parenchymal extinction were also more common in patients with HPS.

20 Conclusions: HPS is associated with intrahepatic vascular changes and with features 21 suggesting severe portal hypertension. These results raise the hypothesis that intrahepatic vascular changes precipitate the development of HPS, opening new therapeutic perspectives for HPS.

24 Keywords: Hepatopulmonary syndrome; cirrhosis; thrombosis; portal hypertension; angiogenesis 


\section{Introduction}

2 Hepatopulmonary syndrome (HPS) is characterized by an arterial oxygenation defect - as

3 defined by an increased alveolar-arterial partial pressure oxygen difference $\geq 15 \mathrm{~mm} \mathrm{Hg}$ in

4 patients $<65$ years and $\geq 20 \mathrm{~mm} \mathrm{Hg}$ in patients $\geq 65$ years - induced by pulmonary vascular

5 dilatations in the context of liver disease ${ }^{1,2}$. This syndrome is observed in $5 \%$ to $32 \%$ of

6 patients with cirrhosis evaluated for liver transplant ${ }^{2-6}$.

7 The pathogenesis of HPS is still poorly understood, which hampers the development of

8 effective treatments. Data on the mechanisms leading to the key features of HPS, namely

9 pulmonary microvascular dilatations and angiogenesis, have been obtained in rats with chronic common bile duct ligation ${ }^{7}$. In this model, pulmonary vasodilatation results from the interaction between an increased release of endothelin-1 by the liver and an enhanced lung

12 endothelin B receptor expression due to the hyperdynamic circulation of cirrhosis ${ }^{8}$.

13 Pulmonary vasodilatation is also associated with increased activity of endothelial nitric oxide

14 (NO) synthase (eNOS) and inducible NO synthase (iNOS), and with enhanced carbon monoxide (CO) production. Pulmonary angiogenesis is accompanied by the accumulation of vascular endothelial growth factor (VEGF)-A in the lungs, and activation of VEGF-A dependent signaling pathways. Placental growth factor (PIGF) also contributes to lung angiogenesis in HPS ${ }^{9}$.

19 Attempts to clarify the pathophysiology of HPS in patients have been scarce. Patients with 20 HPS were found to have elevated levels of exhaled NO ${ }^{10}$, of venous endothelin- $1^{11}$, of 21 soluble VCAM-1 and ICAM- ${ }^{12}$ and of arterial carboxyhemoglobin ${ }^{13}$. However, the source of 22 these soluble mediators is unknown. Complete resolution or significant improvement in gas exchange is almost constant following liver transplant suggesting that the liver itself, or the gut though the portosystemic venous shunts, release mediators resulting in pulmonary 25 changes ${ }^{3}$.

26 In order to better understand the mechanisms involved in HPS, we aimed to characterize the 27 morphological changes occurring in patients with HPS both within the liver - based on 28 explant pathology - and within thorax and abdomen based on pre-transplant imaging. 
1 This study has been approved by the Institutional Review Board of HUPNVS, Paris 7

2 University, AP-HP (\#2017-013).

\section{Methods}

\section{Patients}

This retrospective case-control study included all patients evaluated for liver transplant between January 1997 and December 2015 at Beaujon hospital, Clichy, France. To facilitate matching between cases (HPS) and controls, only patients with a pre-transplant diagnosis of alcohol-related cirrhosis, hepatitis B or C virus-related cirrhosis, non-alcoholic steatohepatitis-related cirrhosis or cryptogenic cirrhosis were included. Diagnosis of cirrhosis was based on clinical examination, laboratory test, imaging and/or liver biopsy. The study protocol conformed to the ethical guidelines of the 1975 Declaration of Helsinki.

Cases were patients with a diagnosis of HPS at least moderately severe based on the following criteria: (i) diagnosis of cirrhosis, as mentioned above; (ii) abnormal arterial oxygenation $\left(\mathrm{PaO}_{2} \leq 70 \mathrm{~mm} \mathrm{Hg}\right.$ and alveolar-arterial oxygen gradient $\geq 15 \mathrm{~mm} \mathrm{Hg}$ in patients $<65$ years and $\geq 20 \mathrm{~mm} \mathrm{Hg}$ in patients $\geq 65$ years) breathing room air, at rest, in the supine and/or standing position; and (iii) contrast-enhanced transthoracic echocardiography showing appearance of microbubbles in the left heart chambers 3 to 6 cycles after right atrial passage, reflecting intrapulmonary vascular dilatations ${ }^{14,15}$. All patients had a thoracic multidetector computed tomography (MDCT) excluding large volume pleural effusion or significant parenchymal changes that could explain hypoxemia. Patients with pulmonary hypertension defined by mean pulmonary pressure $>25 \mathrm{~mm} \mathrm{Hg}$, pulmonary arterial occlusion pressure $<15 \mathrm{mmHg}$ and pulmonary vascular resistance $>240$ dyn second $\mathrm{cm}^{-5}$ were not included in the study.

Control patients had normal $\mathrm{PaO}_{2}(>85 \mathrm{~mm} \mathrm{Hg})$ in supine and upright position. Three controls were matched with one patient with HPS according to the cause of liver disease, calculated model for end-stage liver disease score (MELD) $( \pm 3)$ at evaluation for liver 
1 transplant, and age ( \pm 5 years). In patients with several causes of cirrhosis, matching was

2 performed for the main cause of cirrhosis. MELD values mentioned all along the manuscript

3 are calculated using the formulae previously reported ${ }^{16}$ without extra points for hepatocellular

4 carcinoma or HPS.

\section{Features analyzed}

Clinical, laboratory, hemodynamics features were analyzed. All thoracic and abdominal contrast-enhanced triple phase MDCT performed at evaluation for liver transplant were reviewed by a senior radiologist $(\mathrm{OB})$ unaware of the clinical, laboratory and pathological results. During the study period, samples from explants of liver transplant recipients were systematically collected. For this study, liver samples from 6 or more liver segments were selected. They were retrospectively reviewed by an expert pathologist (VP) unaware of the presence or absence of HPS or of any other clinical, laboratory or imaging result. The extent of liver fibrosis was evaluated by morphometry using picrosirius staining, as reported previously ${ }^{17}$. Factor $V$ Leiden and G20210A prothrombin gene mutations were tested in cases and controls after DNA extraction from frozen samples of explanted livers according to previously reported methods ${ }^{18}$. All details regarding features analyzed are included in supplementary material. (e-Text 1)

\section{Statistical analysis}

Quantitative variables were expressed as median and interquartile range, and categorical variables as absolute and relative frequencies. Comparisons between groups of quantitative variables were performed using the Mann-Whitney $U$ test. Comparisons between groups of qualitative variables were performed using Chi-square and the Fisher exact tests, as appropriate. All tests were two-sided, and significance was set at $p<0.05$. All statistics analyses were performed using the SPSS statistical package 20.0 software (SPSS Inc., Chicago, IL, United States). 


\section{$1 \quad$ Results}

\section{Patients' characteristics}

3 Out of the 2280 patients assessed for liver transplant at our hospital between January 1997

4 and December 2015, including 1355 patients meeting the above mentioned inclusion criteria, 523 had a diagnosis of HPS at least moderately severe. Twenty-one out of these 23 patients

6 had complete pre-transplant imaging. Nineteen patients were transplanted and had 7 explanted liver samples available for review. Finally, 17 patients had both imaging and 8 histological data available for review (e-figure S1: flow chart).

9 These 21 HPS patients with imaging data available and 19 patients with liver sample available were compared with 63 and 57 matched control patients with a pretransplant diagnosis of cirrhosis, respectively. Their clinical, laboratory and hemodynamic features are shown in Table 1. Alveolar-arterial oxygen gradient was above $60 \mathrm{mmHg}$ (corresponding to $\mathrm{PaO}_{2}<50 \mathrm{~mm} \mathrm{Hg}$ breathing room air with $\mathrm{PaCO}_{2}=32 \mathrm{mmHg}$ ) in $71 \%$ and $84 \%$ of the patients with HPS with imaging data and with liver sample available, respectively. HPS patients and control patients did not differ in age, cause and severity of cirrhosis. Alcohol abuse was the leading cause of cirrhosis. Large esophageal varices were more frequent in patients with HPS than in control patients. Hepatocellular carcinoma was common in the control group. This difference can be explained by the matching for the calculated MELD score at evaluation for transplant (no including MELD exception points for HPS or hepatocellular carcinoma). Indeed, patients

21 listed for HPS had a relatively low calculated MELD score and patients listed with a similar calculated MELD score and no HPS were more likely to have hepatocellular carcinoma as an indication for transplant. Laboratory and hemodynamic data were similar in both groups, except for serum creatinine and mean arterial pressure that were slightly higher in control patients. Duration between evaluation before liver transplant and transplant was shorter in HPS patients than in control patients. 


\section{Complete image analysis}

2 Imaging findings are shown in Table 2. Patients with HPS had obstructed intrahepatic portal

3 vein branches, slowed or hepatofugal portal blood flow, and/or large abdominal portocaval

4 shunts two to three-fold more frequently than control patients. Moreover, patients with HPS had larger paraumbilical vein diameter and hepatic artery diameter (Figure 1). Hepatic venous system, right colon, spleen and thorax aspects were not different between the two groups. All these differences, except slowed or hepatofugal hepatic portal blood flow, remained significant when restricting the analyses to the 17 HPS patients with MDCT, Doppler ultrasound and explanted liver samples available for review (data not shown). Thoracic imaging features were not different between patients with HPS and control patients.

\section{Explant pathology}

Histological findings are shown in Tables 3 and 4. Pathological examination of the explanted liver confirmed pretransplant diagnosis of cirrhosis or advanced fibrosis in all but 2 patients. Details on these 2 patients are provided in online e-Table 2.

When comparing the two groups, we found that HPS was associated with a 4-fold higher prevalence of intrahepatic portal venule thrombosis, and a 9-fold higher prevalence of extensive vascular proliferation within fibrous septa. Thickening and thrombosis of centrilobular veins, sinusoidal dilatation, liver parenchymal extinction and features consistent with incomplete septal cirrhosis were also more common in patients with HPS than in control patients (illustrated in Figures 2 and 3). Prevalence of other features was similar between the two groups. When restricting the analyses to the 17 patients having both imaging and histological data available for review, intrahepatic portal venule thrombosis, extensive vascular proliferation within fibrous septa, features consistent with incomplete septal cirrhosis and sinusoidal dilatation remained significantly more frequent in patients with HPS than in control patients. 


\section{Prothrombotic states and effect of anticoagulation}

2 Given the high prevalence of intrahepatic venous obstruction in patients with HPS, we tested

3 Factor V Leiden and G20210A prothrombin gene mutations in 15 patients with HPS and in

452 control patients with available frozen liver. Prevalence of these mutations was not 5 different between the two groups.

6 Eight of 21 patients with HPS received anticoagulation (seven for portal thrombosis and one

7 for deep vein thrombosis). We studied changes in alveolar-arterial oxygen gradient_reflecting 8 gas exchange, between evaluation for liver transplant and liver transplant according to the 9 administration or not of anticoagulation and observed no significant difference, but only three patients had anticoagulation for more than 4 months between the two time-points.

\section{Discussion}

13 In this case control study, we found that HPS is associated with prominent changes in the 14 extrahepatic and intrahepatic vasculature.

Histological changes associated with HPS included intrahepatic portal venules thrombosis, thickening and thrombosis of centrilobular veins, extensive vascular proliferation within fibrous septa, sinusoidal dilatation, liver parenchymal extinction, and features consistent with incomplete septal cirrhosis. Ma and colleagues previously assessed liver histological alterations associated with $\mathrm{HPS}^{19}$. These investigators compared histological findings in livers explanted from 8 patients with cirrhosis and HPS with those from 18 patients with

21 cirrhosis without HPS, matched for age, gender and cause of liver disease. The only difference they observed was a lower prevalence of micronodular cirrhosis in patients with HPS. A lack of power due to a small sample size and the absence of matching for the severity of liver disease in the study by Ma and colleagues may explain the variance between these findings and those of the present study.

26 In the present study, imaging changes associated with HPS included a higher prevalence of 27 obstructed intrahepatic portal branches, of slowed or hepatofugal portal blood flow, and of large abdominal portosystemic shunts, as well as larger paraumbilical vein and hepatic artery 
1 diameters. A similar systematic analysis of imaging findings was performed in patients with 2 portopulmonary hypertension and disclosed a high prevalence of large abdominal 3 portosystemic shunts, but we are not aware of any previous study in patients with HPS ${ }^{20}$. In 4 particular, systematic imaging analyses have not been carried out in the large studies 5 investigating features associated with HPS ${ }^{5,6,21}$. In the present study, obstructed intrahepatic 6 portal branches were observed both at the microscopic and at the macroscopic level 7 indicating a diffuse process of portal venous obstruction.

8 Despite the retrospective, cross-sectional, and observational nature of the present study, our 9 findings suggest that liver vessel involvement should be added to the list of the mechanisms leading to HPS ${ }^{8,22}$. Although our results cannot firmly establish that the intra- and extrahepatic changes associated with HPS precede the development this syndrome, the vascular pattern of damage we observed in patients with HPS raises the hypothesis that obstruction of intrahepatic portal branches and hepatic venules are a primary event in the development of pulmonary changes. Indeed, portal and hepatic venules obstructions have been linked to parenchymal extinction in patients with cirrhosis, and with sinusoidal dilatation in non-cirrhotic patients ${ }^{23,24}$. These venular obstructions might also induce liver hypoxia leading to an angiogenic response responsible for extensive vascular proliferation within fibrous septa ${ }^{25}$. Secondarily, these intrahepatic vascular obstructions may increase intrahepatic vascular resistance, thus worsening portal hypertension and explaining the large esophageal varices, large paraumbilical veins and abdominal portosystemic shunts as well as the slowed or hepatofugal portal blood flow and the liver hyperarterialization observed in patients with HPS ${ }^{26}$. The absence of difference in hepatic venous pressure gradient between patients with HPS and control patients despite more pronounced signs of portal hypertension in HPS patients may be explained by the frequent portal venule obstructions in patients with HPS. Indeed, portosystemic gradient is underestimated by hepatic venous pressure gradient measurement in case of presinusoidal lesions, even in the absence of hepatic venous collaterals, as in our study ${ }^{27-29}$. The similar spleen size between patients with HPS and control patients can be accounted for by the absent or weak correlation between spleen size 
1 and portal pressure in patients with cirrhosis ${ }^{30-32}$. Systemic vascular resistance could not be

2 interpreted in our study since patients with HPS tended to receive more commonly 3 betablockers as they more frequently had large varices. The reason why some patients 4 develop obstructions of intrahepatic portal and hepatic veins remains to be determined 5 although a particular hypercoagulable state can be suspected ${ }^{33}$. Several of the lesions 6 observed in patients with HPS are also commonly encountered in patients with idiopathic non-cirrhotic portal hypertension. Therefore, the identification of factors responsible for liver vascular lesions in HPS might come in the future from a better understanding of the pathophysiology of idiopathic non-cirrhotic portal hypertension. If confirmed by other groups, our findings would provide the rational for future studies testing anticoagulation in patients with HPS. Since no dramatic improvement in hypoxemia was observed in the few patients with HPS treated with anticoagulation in the present study, such a therapy would likely be tested at early steps of HPS development to prevent HPS progression.

In addition to the previously demonstrated role of endothelin 1 and of bacterial translocation in HPS development, the vascular pattern of damage we observed associated with HPS suggests two possible scenarios explaining the pulmonary microvascular dilatations and angiogenesis typical of this syndrome ${ }^{8,12}$. A first possibility could be that the mediators responsible for the pulmonary microvascular dilatations and angiogenesis derive from the gut and reach directly the lungs through the major portosystemic shunts observed in patients with HPS, without being cleared by the liver, as described in HPS associated with Abernethy syndrome. VEGF is unlikely to be this mediator since VEGF levels are lower in the portal vein than in hepatic veins in patients with cirrhosis ${ }^{34}$. The rare development of HPS following TIPS placement in patients with cirrhosis suggests that other factors than the pure derivation of the blood from the gut to the lungs are however needed to induce HPS ${ }^{35}$. A second possibility is that intrahepatic portal vein obstructions in patients with HPS induce liver hypoxia leading to the release by the hypoxic liver of pro-angiogenic/vasodilatatory agents into hepatic veins ${ }^{36}$. The first vascular bed encountered by these mediators is the pulmonary 
1 one. This hypothesis is supported by the activation of the VEGF pathway in the lungs of rats

2 with HPS ${ }^{37}$. The observation of more frequent HPS in patients with liver hypoxia induced by

3 Budd Chiari syndrome (28\%) or hypoxic hepatitis (46\%) than in patients with extrahepatic

4 portal vein thrombosis without cirrhosis (4\%) is consistent with this view ${ }^{38-41}$.

5

6 Conclusion

7 This case-control study shows that HPS is associated with significant intrahepatic vascular

8 changes as well as with features suggesting a severe portal hypertension. Our findings invite

9 to give increased importance to - and to gain further insight into - the obstruction of

10 intrahepatic portal and hepatic venules as an additional pathophysiological mechanism

11 leading to HPS. 


\section{Acknowledgements}

2 We thank Marion Tanguy, Nathalie Colnot and Miguel Albuquerque for superb technical

3 assistance.

4

\section{Authors' contribution:}

6 Dr Clément Lejealle and Pierre Emmanuel Rautou take responsibility for the content of the 7 manuscript including the data and analysis.

8 CL collected the data. CL and PER drafted the manuscript. VP and OB reviewed all explants

9 and imaging, respectively. All authors discussed and critically revised the manuscript.

10 We thank Marion Tanguy, Nathalie Colnot and Miguel Albuquerque for superb technical 11 assistance. 


\section{References}

1. Rodríguez-Roisin R, Krowka MJ, Hervé $P$, Fallon MB. Pulmonary-Hepatic vascular Disorders (PHD). Eur Respir J 2004;24(5):861-880.

2. Rodríguez-Roisin R, Krowka MJ. Hepatopulmonary Syndrome - A Liver-Induced Lung Vascular Disorder. N Engl J Med 2008;358(22):2378-2387.

3. Machicao VI, Balakrishnan M, Fallon MB. Pulmonary complications in chronic liver disease. Hepatology 2014;59(4):1627-1637.

4. Schenk P, Fuhrmann V, Madl C, et al. Hepatopulmonary syndrome: prevalence and predictive value of various cut offs for arterial oxygenation and their clinical consequences. Gut 2002;51(6):853-859.

5. Swanson KL, Wiesner RH, Krowka MJ. Natural history of hepatopulmonary syndrome: Impact of liver transplantation. Hepatology 2005;41(5):1122-1129.

6. Fallon MB, Krowka MJ, Brown RS, et al. Impact of Hepatopulmonary Syndrome on Quality of Life and Survival in Liver Transplant Candidates. Gastroenterology 2008;135(4):1168-1175.

7. Fallon MB, Abrams GA, McGrath JW, Hou Z, Luo B. Common bile duct ligation in the rat: a model of intrapulmonary vasodilatation and hepatopulmonary syndrome. $A m J$ Physiol - Gastrointest Liver Physiol 1997;272(4):G779-G784.

8. Koch DG, Fallon MB. Hepatopulmonary syndrome. Curr Opin Gastroenterol 2014;30(3):260-264.

9. Raevens S, Geerts A, Paridaens A, et al. Placental growth factor inhibition targets pulmonary angiogenesis and represents a novel therapy for hepatopulmonary syndrome in mice. Hepatol Baltim Md 2017;

10. Rolla G, Brussino $L$, Colagrande $P$, et al. Exhaled nitric oxide and oxygenation abnormalities in hepatic cirrhosis. Hepatology 1997;26(4):842-847.

11. Koch DG, Bogatkevich G, Ramshesh V, Lemasters JJ, Uflacker R, Reuben A. Elevated levels of endothelin-1 in hepatic venous blood are associated with intrapulmonary vasodilatation in humans. Dig Dis Sci 2012;57(2):516-523.

12. Raevens S, Coulon S, Van Steenkiste C, et al. Role of angiogenic factors/cell adhesion markers in serum of cirrhotic patients with hepatopulmonary syndrome. Liver Int Off $J$ Int Assoc Study Liver 2015;35(5):1499-1507.

13. Arguedas MR, Drake BB, Kapoor A, Fallon MB. Carboxyhemoglobin levels in cirrhotic patients with and without hepatopulmonary syndrome. Gastroenterology 2005;128(2):328-333.

14. Krowka MJ, Tajik AJ, Dickson ER, Wiesner RH, Cortese DA. Intrapulmonary vascular dilatations (ipvd) in liver transplant candidates. screening by two-dimensional contrastenhanced echocardiography. Chest 1990;97(5):1165-1170. 
15. Abrams GA, Jaffe CC, Hoffer PB, Binder HJ, Fallon MB. Diagnostic utility of contrast echocardiography and lung perfusion scan in patients with hepatopulmonary syndrome. Gastroenterology 1995;109(4):1283-1288.

16. Kamath PS, Wiesner RH, Malinchoc M, et al. A model to predict survival in patients with end-stage liver disease. Hepatol Baltim Md 2001;33(2):464-470.

17. Caballero $T$, Pérez-Milena $A$, Masseroli $M$, et al. Liver fibrosis assessment with semiquantitative indexes and image analysis quantification in sustained-responder and non-responder interferon-treated patients with chronic hepatitis C. J Hepatol $2001 ; 34(5): 740-747$.

18. Nery $F$, Chevret $S$, Condat $B$, et al. Causes and consequences of portal vein thrombosis in 1,243 patients with cirrhosis: results of a longitudinal study. Hepatol Baltim Md 2015;61(2):660-667.

19. Ma C, Crippin JS, Chapman WC, et al. Parenchymal alterations in cirrhotic livers in patients with hepatopulmonary syndrome or portopulmonary hypertension. Liver Transpl 2013;19(7):741-750.

20. Talwalkar JA, Swanson KL, Krowka MJ, Andrews JC, Kamath PS. Prevalence of spontaneous portosystemic shunts in patients with portopulmonary hypertension and effect on treatment. Gastroenterology 2011;141(5):1673-1679.

21. Pascasio JM, Grilo I, López-Pardo FJ, et al. Prevalence and Severity of Hepatopulmonary Syndrome and Its Influence on Survival in Cirrhotic Patients Evaluated for Liver Transplantation. Am J Transplant 2014;14(6):1391-1399.

22. Raevens S, Geerts A, Van Steenkiste C, Verhelst X, Van Vlierberghe H, Colle I. Hepatopulmonary syndrome and portopulmonary hypertension: recent knowledge in pathogenesis and overview of clinical assessment. Liver Int Off J Int Assoc Study Liver 2015;35(6):1646-1660.

23. Verheij J, Schouten JNL, Komuta M, et al. Histological features in western patients with idiopathic non-cirrhotic portal hypertension. Histopathology 2013;62(7):1083-1091.

24. Marzano C, Cazals-Hatem D, Rautou P-E, Valla D-C. The significance of nonobstructive sinusoidal dilatation of the liver: Impaired portal perfusion or inflammatory reaction syndrome. Hepatology 2015;

25. Thabut D, Shah V. Intrahepatic angiogenesis and sinusoidal remodeling in chronic liver disease: new targets for the treatment of portal hypertension? J Hepatol 2010;53(5):976-980.

26. Itai Y, Matsui O. Blood flow and liver imaging. Radiology 1997;202(2):306-314.

27. Sarin SK, Sethi KK, Nanda R. Measurement and correlation of wedged hepatic, intrahepatic, intrasplenic and intravariceal pressures in patients with cirrhosis of liver and non-cirrhotic portal fibrosis. Gut 1987;28(3):260-266.

28. Bissonnette J, Garcia-Pagán JC, Albillos A, et al. Role of the transjugular intrahepatic portosystemic shunt in the management of severe complications of portal hypertension in idiopathic noncirrhotic portal hypertension. Hepatol Baltim Md 2016;64(1):224-231. 
29. Seijo S, Reverter E, Miquel R, et al. Role of hepatic vein catheterisation and transient elastography in the diagnosis of idiopathic portal hypertension. Dig Liver Dis Off $\mathrm{J}$ Ital Soc Gastroenterol Ital Assoc Study Liver 2012;44(10):855-860.

30. Westaby S, Wilkinson SP, Warren R, Williams R. Spleen size and portal hypertension in cirrhosis. Digestion 1978;17(1):63-68.

31. Merkel C, Gatta A, Arnaboldi L, Zuin R. Splenic haemodynamics and portal hypertension in patients with liver cirrhosis and spleen enlargement. Clin Physiol Oxf Engl 1985;5(6):531-539.

32. Gusberg RJ, Peterec SM, Sumpio BE, Meier GH. Splenomegaly and variceal bleeding-hemodynamic basis and treatment implications. Hepatogastroenterology 1994;41(6):573-577.

33. Tripodi A, Mannucci PM. The Coagulopathy of Chronic Liver Disease. $N$ Engl J Med $2011 ; 365(2): 147-156$.

34. Mortensen C, Karlsen S, Grønbæk H, et al. No difference in portal and hepatic venous bacterial DNA in patients with cirrhosis undergoing transjugular intrahepatic portosystemic shunt insertion. Liver Int Off J Int Assoc Study Liver 2013;33(9):1309_ 1315.

35. Tsauo J, Weng $\mathrm{N}$, Ma H, Jiang $\mathrm{M}$, Zhao $\mathrm{H}$, Li X. Role of Transjugular Intrahepatic Portosystemic Shunts in the Management of Hepatopulmonary Syndrome: A Systemic Literature Review. J Vasc Interv Radiol JVIR 2015;

36. Corpechot C, Barbu V, Wendum D, et al. Hypoxia-induced VEGF and collagen I expressions are associated with angiogenesis and fibrogenesis in experimental cirrhosis. Hepatology 2002;35(5):1010-1021.

37. Zhang J, Luo B, Tang $\mathrm{L}$, et al. Pulmonary angiogenesis in a rat model of hepatopulmonary syndrome. Gastroenterology 2009;136(3):1070-1080.

38. Krowka MJ. Hepatopulmonary syndrome and extrahepatic vascular abnormalities. Liver Transplant Off Publ Am Assoc Study Liver Dis Int Liver Transplant Soc 2001;7(7):656657.

39. Gupta D, Vijaya DR, Gupta R, et al. Prevalence of hepatopulmonary syndrome in cirrhosis and extrahepatic portal venous obstruction. Am $J$ Gastroenterol 2001;96(12):3395-3399.

40. De BK, Sen S, Biswas $¥$ PK, et al. Occurrence of hepatopulmonary syndrome in BuddChiari syndrome and the role of venous decompression. Gastroenterology 2002;122(4):897-903.

41. Fuhrmann V, Madl C, Mueller C, et al. Hepatopulmonary Syndrome in Patients With Hypoxic Hepatitis. Gastroenterology 2006;131(1):69-75. 
1 TABLE 1 Patients' clinical, laboratory and hemodynamics features at

2 evaluation for transplantation

3

\begin{tabular}{|c|c|c|c|c|c|c|c|c|}
\hline \multirow[b]{2}{*}{ Variable } & \multicolumn{4}{|c|}{ Complete image analysis } & \multicolumn{4}{|c|}{ Explant Pathology } \\
\hline & $\mathbf{n}^{*}$ & $\begin{array}{c}\text { Control } \\
\text { patients } \\
(n=63)\end{array}$ & $\begin{array}{c}\text { HPS } \\
\text { patients } \\
(n=21)\end{array}$ & $p$ & $\mathrm{n}^{*}$ & $\begin{array}{l}\text { Control } \\
\text { patients } \\
(n=57)\end{array}$ & $\begin{array}{c}\text { HPS } \\
\text { patients } \\
(n=19)\end{array}$ & $p$ \\
\hline Age (years) & 84 & $56(50-61)$ & $53(49-59)$ & 0.20 & 76 & $53(49-59)$ & $51(49-54)$ & 0.25 \\
\hline Female gender & 84 & $17(27)$ & $9(43)$ & 0.17 & 76 & $13(23)$ & $10(53)$ & 0.01 \\
\hline \multicolumn{9}{|l|}{ Arterial blood gas } \\
\hline Upright $\mathrm{PaO}_{2}(\mathrm{~mm} \mathrm{Hg})$ & 70 & $\begin{array}{c}105 \\
(98-118)\end{array}$ & $\begin{array}{c}60 \\
(49-67)\end{array}$ & $<0.01$ & 65 & $\begin{array}{c}106 \\
(98-118)\end{array}$ & $\begin{array}{c}52 \\
(46-60)\end{array}$ & $<0.01$ \\
\hline Upright $\mathrm{A}-\mathrm{a} \mathrm{PO}_{2}(\mathrm{~mm} \mathrm{Hg})$ & 70 & $3(0-12)$ & $62(50-66)$ & $<0.01$ & 65 & $2(0-12)$ & $66(59-74)$ & $<0.01$ \\
\hline Upright $\mathrm{SaO}_{2}(\%)$ & 70 & 99 (98-99) & $91(88-95)$ & $<0.01$ & 73 & 99 (98-99) & $88(85-95)$ & $<0.01$ \\
\hline \multicolumn{9}{|l|}{ Hemodynamic data } \\
\hline MAP (mm Hg) & 70 & $89(82-96)$ & $84(76-92)$ & 0.046 & 62 & $90(85-97)$ & $83(72-92)$ & 0.046 \\
\hline HVPG (mm Hg) & 67 & $\begin{array}{c}16 \\
(12-22)\end{array}$ & $\begin{array}{c}17 \\
(12-19)\end{array}$ & 0.77 & 57 & $\begin{array}{c}16 \\
(13-22)\end{array}$ & $\begin{array}{c}13 \\
(10.5-17.7)\end{array}$ & 0.18 \\
\hline RAP (mm Hg) & 50 & $5(3-10)$ & $6(3-8)$ & 0.75 & 38 & $8(3-10)$ & $8(5-9)$ & 0.96 \\
\hline MPAP (mm Hg) & 61 & $\begin{array}{c}17 \\
(13-23)\end{array}$ & $\begin{array}{c}15 \\
(12-20)\end{array}$ & 0.44 & 53 & $\begin{array}{c}17 \\
(14-23)\end{array}$ & $\begin{array}{c}16 \\
(13-19)\end{array}$ & 0.41 \\
\hline PWP (mm Hg) & 61 & $10(7-14)$ & $10(8-13)$ & 0.84 & 53 & $10(8-15)$ & $10(9-15)$ & 0.97 \\
\hline $\mathrm{Cl}\left(\mathrm{L} / \mathrm{min} / \mathrm{m}^{2}\right)$ & 61 & $\begin{array}{c}3.5 \\
(2.8-4.6)\end{array}$ & $\begin{array}{c}4.2 \\
(3-4.8)\end{array}$ & 0.29 & 50 & $\begin{array}{c}3.8 \\
(3.2-4.8)\end{array}$ & $\begin{array}{c}3.8 \\
(2.9-4.7)\end{array}$ & 0.75 \\
\hline SVR (dyn.s. $\left.\mathrm{cm}^{-5}\right)$ & 60 & $\begin{array}{c}1060 \\
(700-1300)\end{array}$ & $\begin{array}{c}840 \\
(630-1220)\end{array}$ & 0.21 & 50 & $\begin{array}{c}910 \\
(700-1170)\end{array}$ & $\begin{array}{c}880 \\
(630-1320)\end{array}$ & 0.65 \\
\hline PVR (dyn.s.cm ${ }^{-5}$ ) & 59 & $\begin{array}{c}85 \\
(54-144)\end{array}$ & $\begin{array}{c}73 \\
(47-122)\end{array}$ & 0.47 & 49 & $\begin{array}{c}84.2 \\
(51-146)\end{array}$ & $\begin{array}{c}77.2 \\
(47-115)\end{array}$ & 0.79 \\
\hline \multicolumn{9}{|l|}{ Causes of cirrhosis** } \\
\hline Alcohol abuse & 84 & $43(68)$ & $15(71)$ & 0.78 & 76 & $32(56)$ & $11(58)$ & 0.89 \\
\hline Hepatitis B or C virus & 84 & $15(24)$ & $5(24)$ & 1.00 & 76 & $19(33)$ & $6(32)$ & 0.89 \\
\hline Cryptogenic & 84 & $6(10)$ & $2(10)$ & 1.00 & 76 & $6(10)$ & $2(10)$ & 1.00 \\
\hline $\mathrm{NASH}$ & 84 & $12(19)$ & $4(19)$ & 1.00 & 76 & $10(18)$ & $2(10)$ & 0.71 \\
\hline \multicolumn{9}{|l|}{ Severity of cirrhosis } \\
\hline Child-Pugh A & 84 & $12(19)$ & $3(14)$ & 0.75 & 76 & $12(21)$ & $3(16)$ & 1.00 \\
\hline Child-Pugh B & 84 & $28(44)$ & $10(48)$ & 0.80 & 76 & $23(40)$ & $9(47)$ & 0.59 \\
\hline Child -Pugh C & 84 & $23(37)$ & $8(38)$ & 0.90 & 76 & $22(39)$ & $7(37)$ & 0.89 \\
\hline MELD score (unadjusted) & 84 & $13(10-16)$ & $13(10-16)$ & 0.89 & 76 & $13(10-17)$ & $14(10-16)$ & 0.88 \\
\hline \multicolumn{9}{|l|}{ Complications of cirrhosis } \\
\hline Ascites & 84 & $46(73)$ & $16(76)$ & 0.77 & 76 & $38(67)$ & $12(63)$ & 0.79 \\
\hline Refractory ascites & 84 & $28(44)$ & $5(24)$ & 0.09 & 76 & $20(35)$ & $4(21)$ & 0.25 \\
\hline History of SBP & 84 & $16(25)$ & $5(24)$ & 0.88 & 76 & $13(23)$ & $3(16)$ & 0.75 \\
\hline History of encephalopathy & 84 & $28(44)$ & $12(57)$ & 0.31 & 76 & $22(39)$ & $9(47)$ & 0.50 \\
\hline Chronic encephalopathy & 84 & $6(10)$ & $1(5)$ & 0.67 & 76 & $4(7)$ & $0(0)$ & 0.57 \\
\hline Large esophageal varices & 83 & $38(61)$ & $18(86)$ & 0.04 & 76 & $37(65)$ & $16(84)$ & 0.11 \\
\hline History of variceal bleeding & 84 & $18(29)$ & $10(48)$ & 0.11 & 76 & $19(33)$ & $9(47)$ & 0.27 \\
\hline $\mathrm{HCC}$ & 84 & $28(44)$ & $5(24)$ & 0.09 & 76 & $27(47)$ & $3(16)$ & 0.02 \\
\hline HCC treatment & 84 & $20(32)$ & $2(10)$ & 0.04 & 76 & $22(39)$ & $1(5)$ & $<0.01$ \\
\hline TIPS & 82 & $3(5)$ & $0(0)$ & 1.00 & 74 & $3(5)$ & $0(0)$ & 1.00 \\
\hline Hepatorenal syndrome & 84 & $6(10)$ & $0(0)$ & 0.32 & 76 & $3(5)$ & $0(0)$ & 0.57 \\
\hline Hydrothorax & 84 & $6(10)$ & $2(10)$ & 1.00 & 76 & $6(10)$ & $1(5)$ & 0.67 \\
\hline \multicolumn{9}{|l|}{ Comorbidities } \\
\hline BMI $\left(\mathrm{kg} / \mathrm{m}^{2}\right)$ & 75 & $26(23-29)$ & $24(22-29)$ & 0.7 & 75 & $26(23-29)$ & $25(22-28)$ & 0.26 \\
\hline Smoking & 82 & $35(56)$ & $11(58)$ & 0.86 & 74 & $34(60)$ & $10(56)$ & 0.95 \\
\hline COPD & 83 & $4(6)$ & $3(15)$ & 0.35 & 75 & $4(7)$ & $3(16)$ & 0.35 \\
\hline
\end{tabular}


Arterial hypertension

Coronary artery disease

History of VTE

Laboratory data

Serum bilirubin $(\mu \mathrm{mol} / \mathrm{L})$

Serum albumin $(g / L)$

INR

Platelet count $\left(10^{9} / \mathrm{L}\right)$

Alphafetoprotein $(\mu \mathrm{g} / \mathrm{L})$

Treatment

Diuretics

Prophylactic antibiotics

Beta blockers

Anticoagulation

Interval between evaluation before $\mathrm{LT}$ and $\mathrm{LT}$
Diabetes

Serum creatinine $(\mu \mathrm{mol} / \mathrm{L})$

\begin{tabular}{l|c|c|c|c|c|c|c}
83 & $16(25)$ & $5(25)$ & 0.97 & 75 & $14(25)$ & $3(17)$ & 0.75 \\
83 & $24(38)$ & $6(30)$ & 0.51 & 75 & $18(32)$ & $4(22)$ & 0.45 \\
82 & $6(10)$ & $2(10)$ & 1.00 & 74 & $7(12)$ & $0(0)$ & 0.19 \\
83 & $2(3)$ & $2(10)$ & 0.24 & 75 & $2(4)$ & $2(11)$ & 0.24 \\
& & & & & & & \\
84 & $32(16-46)$ & $38(22-58)$ & 0.09 & 76 & $36(17-51)$ & $38(23-57)$ & 0.24 \\
84 & $71(63-91)$ & $65(55-75)$ & 0.06 & 76 & $71(62-90)$ & $60(54-73)$ & $<0.01$ \\
79 & $30(25-35)$ & $28(23-35)$ & 0.86 & 72 & $30(25-33)$ & $31(25-37)$ & 0.40 \\
84 & 1.4 & 1.4 & 0.73 & 76 & 1.4 & 1.4 & 0.88 \\
83 & $(1.2-1.6)$ & $(1.2-1.5)$ & $0.73-1.7)$ & $(1.2-1.6)$ & 0.77 \\
76 & $89(68-127)$ & $89(59-120)$ & 0.68 & 75 & $81(66-116)$ & $89(58-124)$ & 0.15 \\
& $5(3-13)$ & $3(2-5)$ & 0.15 & 69 & $5(3-15)$ & $3(2-6)$ & 0.60 \\
84 & $34(54)$ & $11(52)$ & 0.90 & 76 & $31(54)$ & $9(47)$ & 0.60 \\
84 & $13(21)$ & $3(14)$ & 0.75 & 76 & $11(19)$ & $3(16)$ & 1.00 \\
84 & $37(59)$ & $16(76)$ & 0.15 & 76 & $34(60)$ & $14(74)$ & 0.27 \\
84 & $14(22)$ & $8(38)$ & 0.15 & 76 & $12(21)$ & $7(37)$ & 0.22 \\
82 & $7.5(5-11)$ & $4.4(2-8)$ & 0.03 & 75 & $7.5(5-11)$ & $4.3(2-8)$ & 0.01
\end{tabular}

${ }^{*}$ Number of patients with available data, ${ }^{* *}$ Some patients had several causes of cirrhosis

Variables are expressed as median (interquartile range) or $n(\%)$

Abbreviations: $\mathrm{A}-\mathrm{a} \mathrm{PO}_{2}$, alveolar-arterial gradient $\mathrm{BMI}$, body mass index; $\mathrm{Cl}$, cardiac index; COPD, chronic obstructive pulmonary disease; HCC, hepatocellular carcinoma; HPS, hepatopulmonary syndrome; HVPG, hepatic venous pressure gradient; EV, esophageal variceal; EVL, endoscopic variceal ligation; INR, international normalized ratio; LT, liver transplant; MAP, mean arterial pressure; MPAP, mean pulmonary artery pressure; $\mathrm{PaO} 2$, arterial partial pressure of oxygen; PVR, pulmonary vascular resistance; PWP, pulmonary wedge pressure; $\mathrm{RAP}$, right atrial pressure; SaO2, arterial oxygen saturation; SBP, spontaneous bacterial peritonitis; SVR, systemic vascular resistance; TIPS, transjugular intrahepatic portosystemic shunt; VTE, venous thromboembolism; 
TABLE 2 Abdominal and thoracic imaging in patients with HPS and in control patients

\begin{tabular}{|c|c|c|c|c|}
\hline Variable & $\begin{array}{c}\text { Number of } \\
\text { patients with } \\
\text { available data }\end{array}$ & $\begin{array}{l}\text { Control } \\
\text { patients } \\
(n=63)\end{array}$ & $\begin{array}{l}\text { HPS patients } \\
\qquad(n=21)\end{array}$ & $p$ \\
\hline \multicolumn{5}{|l|}{ Liver morphology } \\
\hline Liver morphologic changes & 84 & $62(99)$ & $21(100)$ & 1.00 \\
\hline Irregular liver surface & 84 & $57(90)$ & $17(81)$ & 0.26 \\
\hline Large parenchymal extinction & 84 & $16(25)$ & $6(29)$ & 0.77 \\
\hline \multicolumn{5}{|l|}{ Arterial vascularization } \\
\hline Hepatic artery diameter (mm) & 83 & $5.6(5.0-6.7)$ & $7.0(6.0-7.5)$ & 0.001 \\
\hline $\begin{array}{l}\text { Heterogeneous liver perfusion } \\
\text { pattern }\end{array}$ & 83 & $2(3)$ & $1(5)$ & 1.00 \\
\hline $\begin{array}{l}\text { Arterioportal or arteriovenous } \\
\text { shunts }\end{array}$ & 83 & $3(5)$ & $1(5)$ & 1.00 \\
\hline \multicolumn{5}{|l|}{ Portal venous system } \\
\hline Main portal vein thrombosis & 84 & $15(24)$ & $7(33)$ & 0.39 \\
\hline Portal vein diameter (mm) & 83 & $15(12-17)$ & $15(10-18)$ & 1.00 \\
\hline Portal branch thrombosis & 84 & $10(16)$ & $3(14)$ & 1.00 \\
\hline $\begin{array}{l}\text { Obstructed intrahepatic portal } \\
\text { branches }\end{array}$ & 82 & $15(24)$ & $12(60)$ & 0.03 \\
\hline $\begin{array}{l}\text { Splenic and/or mesenteric venous } \\
\text { thrombosis }\end{array}$ & 84 & $6(10)$ & $11(17)$ & 0.35 \\
\hline Portal cavernoma & 84 & $6(10)$ & $1(5)$ & 0.67 \\
\hline $\begin{array}{l}\text { Slowed or hepatofugal portal } \\
\text { blood flow }\end{array}$ & 65 & $14(27)$ & $8(57)$ & 0.05 \\
\hline \multicolumn{5}{|l|}{ Hepatic venous system } \\
\hline Hepatic vein thrombosis & 84 & $1(1.5)$ & $0(0)$ & 1.00 \\
\hline Obstructed hepatic vein & 84 & $22(35)$ & $6(29)$ & 0.59 \\
\hline Hepatic venous collaterals & 84 & $0(0)$ & $0(0)$ & 1.00 \\
\hline Portovenous shunts & 83 & $1(1.5)$ & $1(5)$ & 0.44 \\
\hline \multicolumn{5}{|l|}{ Abdominal portosystemic shunts } \\
\hline Paraumbilical vein diameter $(\mathrm{mm})$ & 82 & $2(0-5)$ & $4.5(2-6.5)$ & 0.01 \\
\hline Portosystemic shunts $>10 \mathrm{~mm}$ & 82 & $16(25)$ & $13(65)$ & 0.01 \\
\hline \multicolumn{5}{|l|}{ Spleen } \\
\hline Height (mm) & 84 & $\begin{array}{c}144 \\
(130-170)\end{array}$ & $\begin{array}{c}137 \\
(124-171)\end{array}$ & 0.44 \\
\hline Width $(\mathrm{mm})$ & 84 & $61(52-70)$ & $60(52-71)$ & 0.72 \\
\hline \multicolumn{5}{|l|}{ Right colon wall thickness } \\
\hline Wall thickness $(\mathrm{mm})$ & 84 & $2(2-2)$ & $2(2-12)$ & 0.08 \\
\hline \multicolumn{5}{|l|}{ Intrathoracic changes } \\
\hline Pulmonary artery diameter (mm) & 83 & $28(27-31)$ & $28(27-30)$ & 0.79 \\
\hline Azygos vein diameter (mm) & 83 & $10(9-11)$ & $10(9-11)$ & 0.88 \\
\hline Intrathoracic portosystemic shunts & 84 & $14(22)$ & $7(33)$ & 0.30 \\
\hline Hydrothorax & 84 & $10(16)$ & $6(29)$ & 0.21 \\
\hline
\end{tabular}

Variables are expressed as median (interquartile range) or $n$ (\%).

Abbreviations: HPS, hepatopulmonary syndrome 
TABLE 3 Histological liver vascular changes in patients with HPS and in control patients

\begin{tabular}{|c|c|c|c|c|}
\hline Variable & $\begin{array}{c}\text { Number of } \\
\text { patients with } \\
\text { available data }\end{array}$ & $\begin{array}{c}\text { Control } \\
\text { patients } \\
(n=57)\end{array}$ & $\begin{array}{l}\text { HPS patients } \\
\qquad(n=19)\end{array}$ & $p$ \\
\hline Hepatic artery thrombosis & 76 & $2(3)$ & $1(5)$ & 1.00 \\
\hline Hepatic artery wall thickening & 76 & $5(9)$ & $1(5)$ & 1.00 \\
\hline \multicolumn{5}{|l|}{ Main portal vein thrombosis } \\
\hline Absence & 76 & $40(70)$ & $11(58)$ & \\
\hline Partial & 76 & $15(27)$ & $8(42)$ & 0.34 \\
\hline Complete & 76 & $2(3)$ & $0(0)$ & \\
\hline Main portal vein wall thickening & 76 & $8(14)$ & $4(21)$ & 0.48 \\
\hline Hepatic vein thrombosis & 76 & $2(3)$ & $0(0)$ & 1.00 \\
\hline Hepatic vein wall thickening & 76 & $1(2)$ & $0(0)$ & 1.00 \\
\hline \multicolumn{5}{|c|}{ Intrahepatic portal venule thrombosis } \\
\hline Absence & 76 & $50(88)$ & $10(53)$ & \\
\hline Mild & 76 & $6(10)$ & $8(42)$ & 0.005 \\
\hline Severe or diffuse & 76 & $1(2)$ & $1(5)$ & \\
\hline \multicolumn{5}{|c|}{ Intrahepatic portal venule wall thickening } \\
\hline Absence & 76 & $21(37)$ & $5(26)$ & \\
\hline Mild & 76 & $29(51)$ & $7(37)$ & 0.06 \\
\hline Severe or diffuse & 76 & $7(12)$ & $7(37)$ & \\
\hline \multicolumn{5}{|l|}{ Centrilobular venule thrombosis } \\
\hline Absence & 76 & $42(74)$ & $11(58)$ & \\
\hline Mild & 76 & $13(23)$ & $3(16)$ & 0.01 \\
\hline Severe or diffuse & 76 & $2(3)$ & $5(26)$ & \\
\hline \multicolumn{5}{|l|}{ Centrilobular venule wall thickening } \\
\hline Absence & 76 & $34(60)$ & $7(37)$ & \\
\hline Mild & 76 & $17(30)$ & $5(26)$ & 0.03 \\
\hline Severe or diffuse & 76 & $6(10)$ & $7(37)$ & \\
\hline \multicolumn{5}{|l|}{ Sinusoidal dilatation } \\
\hline Absence & 76 & $32(56)$ & $5(26)$ & 0.02 \\
\hline Present & 76 & $25(44)$ & $14(74)$ & \\
\hline \multicolumn{5}{|c|}{ Vascular proliferation within fibrous septa } \\
\hline Absence & 76 & $16(28)$ & $1(6)$ & \\
\hline Mild & 76 & $38(67)$ & $9(47)$ & $<0.001$ \\
\hline Extensive & 76 & $3(5)$ & $9(47)$ & \\
\hline
\end{tabular}

Variables are expressed as median (interquartile range) or $\mathrm{n}(\%)$.

Abbreviations: HPS, hepatopulmonary syndrome 
TABLE 4 Other liver histological features in patients with HPS and in control patients

\begin{tabular}{|c|c|c|c|c|}
\hline Variable & $\begin{array}{c}\text { Number of } \\
\text { patients with } \\
\text { available data }\end{array}$ & $\begin{array}{l}\text { Control } \\
\text { patients } \\
(n=57)\end{array}$ & $\begin{array}{l}\text { HPS patients } \\
\qquad(n=19)\end{array}$ & $p$ \\
\hline Liver weight (gram) & 74 & $\begin{array}{c}1227 \\
(1025-1605)\end{array}$ & $\begin{array}{c}1117 \\
(915-1462)\end{array}$ & 0.35 \\
\hline \multicolumn{5}{|l|}{ Liver aspect } \\
\hline Macronodular & 73 & $13(24)$ & $2(12)$ & 0.49 \\
\hline Micronodular & 73 & $30(54)$ & $12(76)$ & 0.21 \\
\hline Mixed & 73 & $12(22)$ & $2(12)$ & 0.50 \\
\hline \multicolumn{5}{|l|}{ Activity score } \\
\hline A0, no activity & 71 & $12(22)$ & $6(35)$ & \\
\hline A1, mild activity & 71 & $34(63)$ & $10(59)$ & \\
\hline A2, moderate activity & 71 & $6(11)$ & $1(6)$ & 0.37 \\
\hline A3, severe activity & 71 & $2(4)$ & $0(0)$ & \\
\hline \multicolumn{5}{|l|}{ Fibrosis score } \\
\hline F2, portal fibrosis with few septa & 76 & $1(2)$ & $1(5)$ & \\
\hline F3, numerous septa without cirrhosis & 76 & $2(4)$ & $1(5)$ & 0.66 \\
\hline F4, cirrhosis & 76 & $54(94)$ & $17(90)$ & \\
\hline \multicolumn{5}{|l|}{ Laennec score } \\
\hline $4 a$ mild & 71 & $24(44)$ & $5(29)$ & \\
\hline $4 \mathrm{~b}$ moderate & 71 & $23(43)$ & $8(47)$ & 0.51 \\
\hline $4 c$ severe & 71 & $7(13)$ & $4(24)$ & \\
\hline \multicolumn{5}{|l|}{ Perisinusoidal fibrosis } \\
\hline $\begin{array}{l}\text { Absence } \\
\text { Mild } \\
\text { Severe or diffuse }\end{array}$ & $\begin{array}{l}76 \\
76 \\
76\end{array}$ & $\begin{array}{l}15(26) \\
29(51) \\
13(23)\end{array}$ & $\begin{array}{l}5(26) \\
9(48) \\
5(26)\end{array}$ & 0.95 \\
\hline \multicolumn{5}{|l|}{ Morphometric analysis } \\
\hline Fibrosis (\%) & 76 & $30(23-36)$ & $35(24-45)$ & 0.38 \\
\hline Incomplete septal cirrhosis & 76 & $1(2)$ & $3(16)$ & 0.046 \\
\hline Parenchymal extinction areas & 76 & $16(28)$ & $10(53)$ & 0.05 \\
\hline \multicolumn{5}{|l|}{ Steatosis } \\
\hline$<5 \%$ & 76 & $36(63)$ & $14(74)$ & \\
\hline $5-33 \%$ & 76 & $18(31)$ & $3(16)$ & 036 \\
\hline $34-66 \%$ & 76 & $2(4)$ & $2(10)$ & 0.30 \\
\hline$>67 \%$ & 76 & $1(2)$ & $0(0)$ & \\
\hline \multicolumn{5}{|l|}{ Hepatocytes ballooning } \\
\hline Absence & 76 & $26(45)$ & $14(74)$ & \\
\hline Mild (size > N, <2N) & 76 & $20(35)$ & $4(21)$ & 0.09 \\
\hline Severe $($ size $>2 \mathrm{~N})$ & 76 & $11(20)$ & $1(5)$ & \\
\hline \multicolumn{5}{|l|}{ Lobular inflammation } \\
\hline Absence & 76 & $40(70)$ & $14(74)$ & \\
\hline Mild ( $\leq 2$ foci / $20 \times$ field) & 76 & $15(26)$ & $5(26)$ & 0.71 \\
\hline Severe $(>2$ foci $/ 20 \times$ field $)$ & 76 & $2(4)$ & $0(0)$ & \\
\hline Ductular proliferation & & & & \\
\hline
\end{tabular}




\begin{tabular}{l|c|c|c|c}
\multicolumn{1}{l|}{ Absence } & 76 & $27(47)$ & $10(53)$ & \\
$\quad$ Mild & 76 & $22(39)$ & $7(37)$ & 0.89 \\
$\quad$ Severe or diffuse & 76 & $8(14)$ & $2(10)$ & \\
Bile deposition & 76 & $13(23)$ & $1(5)$ & 0.17 \\
Iron deposition & 76 & $17(30)$ & $4(21)$ & 0.46 \\
\hline
\end{tabular}

Variables are expressed as median (interquartile range) or $\mathrm{n}(\%)$.

Abbreviations: HPS, hepatopulmonary syndrome 


\section{Figure legends}

FIGURE 1 Imaging features associated with hepatopulmonary syndrome (HPS).

4 Axial abdominal contrast-enhanced multidetector computed tomography during portal phase (A, B, C, $D, G, H)$ and arterial phase $(E, F)$ in patients with cirrhosis without $(A, C, E, G)$ and with $(B, D, F, H)$ HPS.

(A) Visible portal branches (arrowheads); (B) Invisible portal branches (arrows); (C) Thin splenorenal shunts (arrow); (D) Large splenorenal shunts (arrow); (E) Thin paraumbilical vein (arrowhead); (F) Large paraumbilical vein (arrow); (G) "Normal" hepatic artery (arrowhead); (H) Enlarged hepatic artery 10 (arrow).

11

FIGURE 2 Intrahepatic vascular changes associated with hepatopulmonary syndrome (HPS). Haematoxylin and eosin staining of liver explants from patients with cirrhosis without $(A, C, E, G)$ and with (B, D, F, H) HPS.

(A) Patent intrahepatic portal venule (arrowhead) (Magnification x140); (B) Intrahepatic portal venules thrombosis (arrows) (Magnification x280); (C) Fibrous septa without vascular proliferation (arrowheads) (Magnification x80); (D) Vascular proliferation (increased number of venous channels) within fibrous septa (arrow) (Magnification x80); (E) "Normal" centrilobular venule (arrowheads) (Magnification x140); (F) Wall thickening of centrilobular venule (arrows) (Magnification x140); (G) Permeable intrahepatic hepatic venule (arrowheads) (Magnification x280); $(\mathrm{H})$ Intrahepatic hepatic venule thrombosis (arrows) (Magnification $\times 140)$.

\section{FIGURE 3 Architectural and lobular changes associated with hepatopulmonary syndrome}

(HPS). Haematoxylin and eosin (A, B, E, F) and Picrosirius (C, D) staining of liver explants from patients with cirrhosis without (A, C, E) and with (B, D, F) HPS.

(A) No dilated liver sinusoids (arrowheads) (Magnification x190); (B) Centrilobular sinusoidal dilatation (arrows) (Magnification x190); (C) "Usual" fibrous septa (arrows) surrounding hepatocytes nodules (arrowheads) (Magnification x28); (D) Large area of confluent fibrosis (arrows) with small nodules of hepatocytes (arrowheads) (Magnification x28); (E) "Usual" complete septa delimiting hepatocytes nodules (arrowheads) (Magnification x56); (F) Thin and incomplete septa (arrows) delimiting hepatocytes nodules (Magnification x56). 


\section{Figure 1}

Control patients

\section{HPS patients}

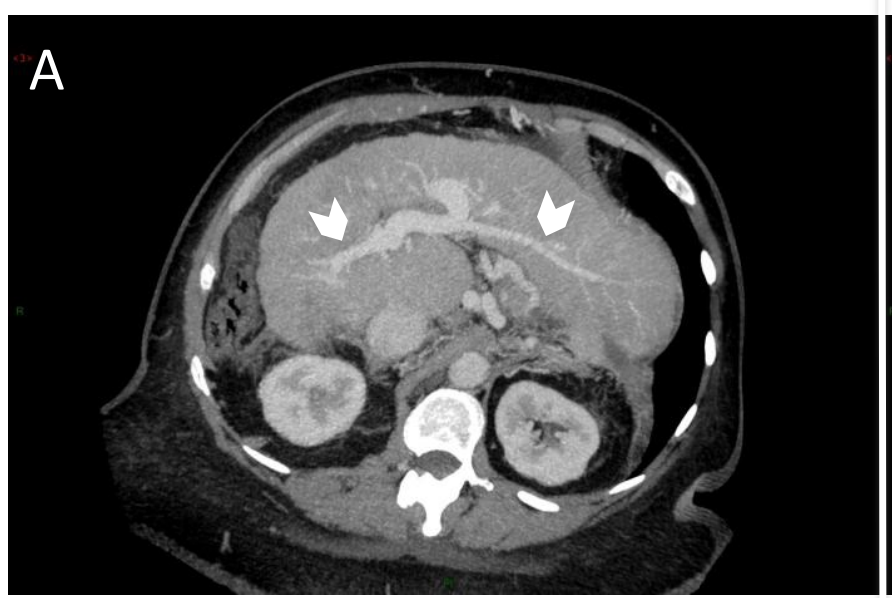

B

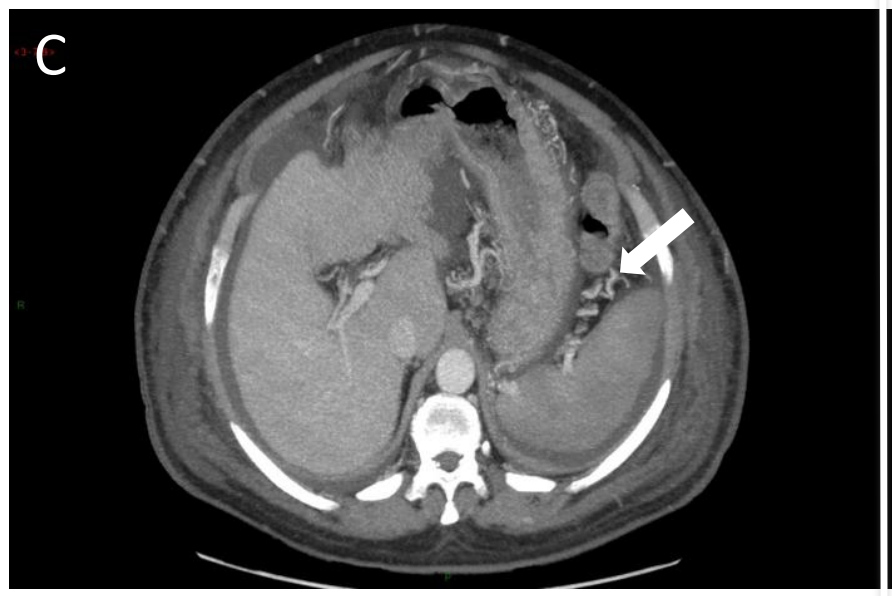

D

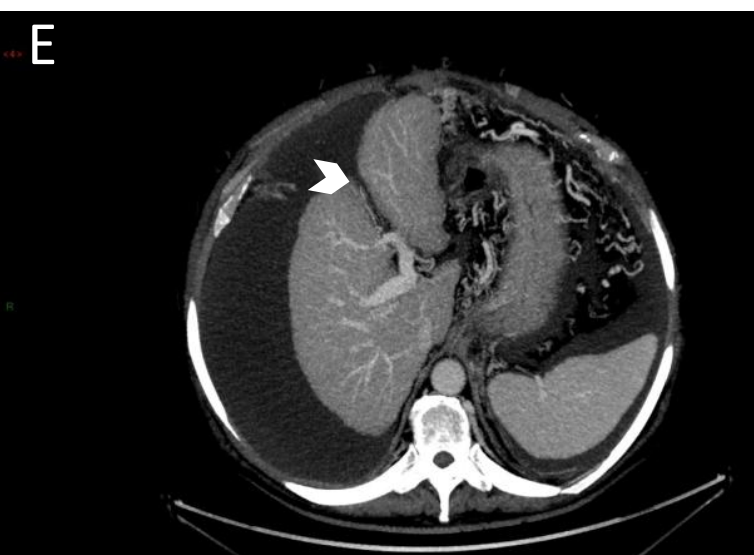

$\mathrm{F}$
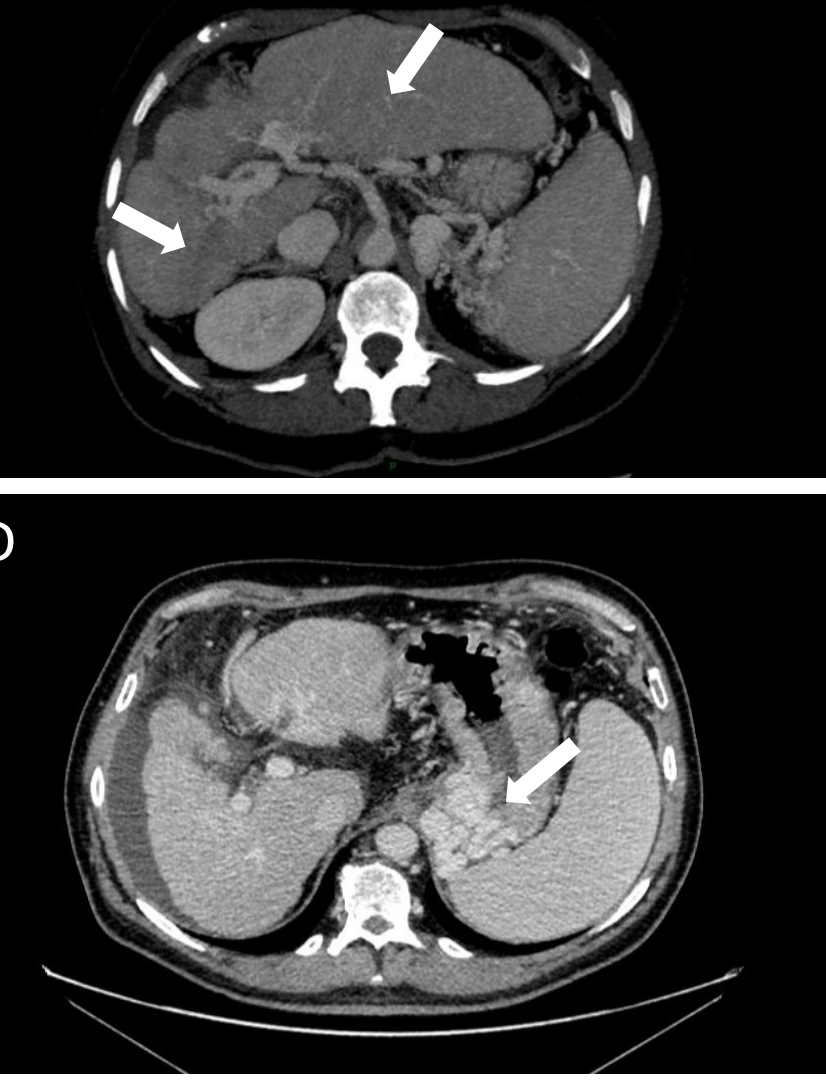
(

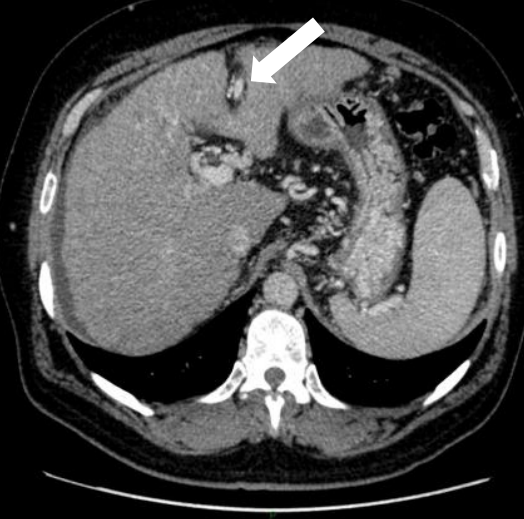

G

H
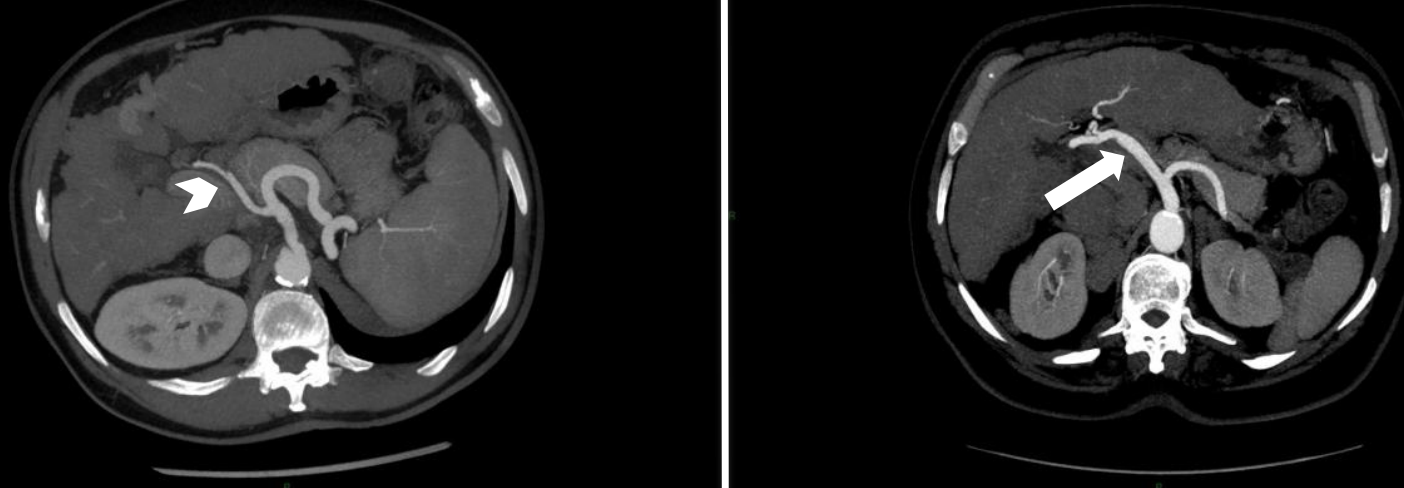


\section{Figure 2}

\section{Control patients}

\section{HPS patients}
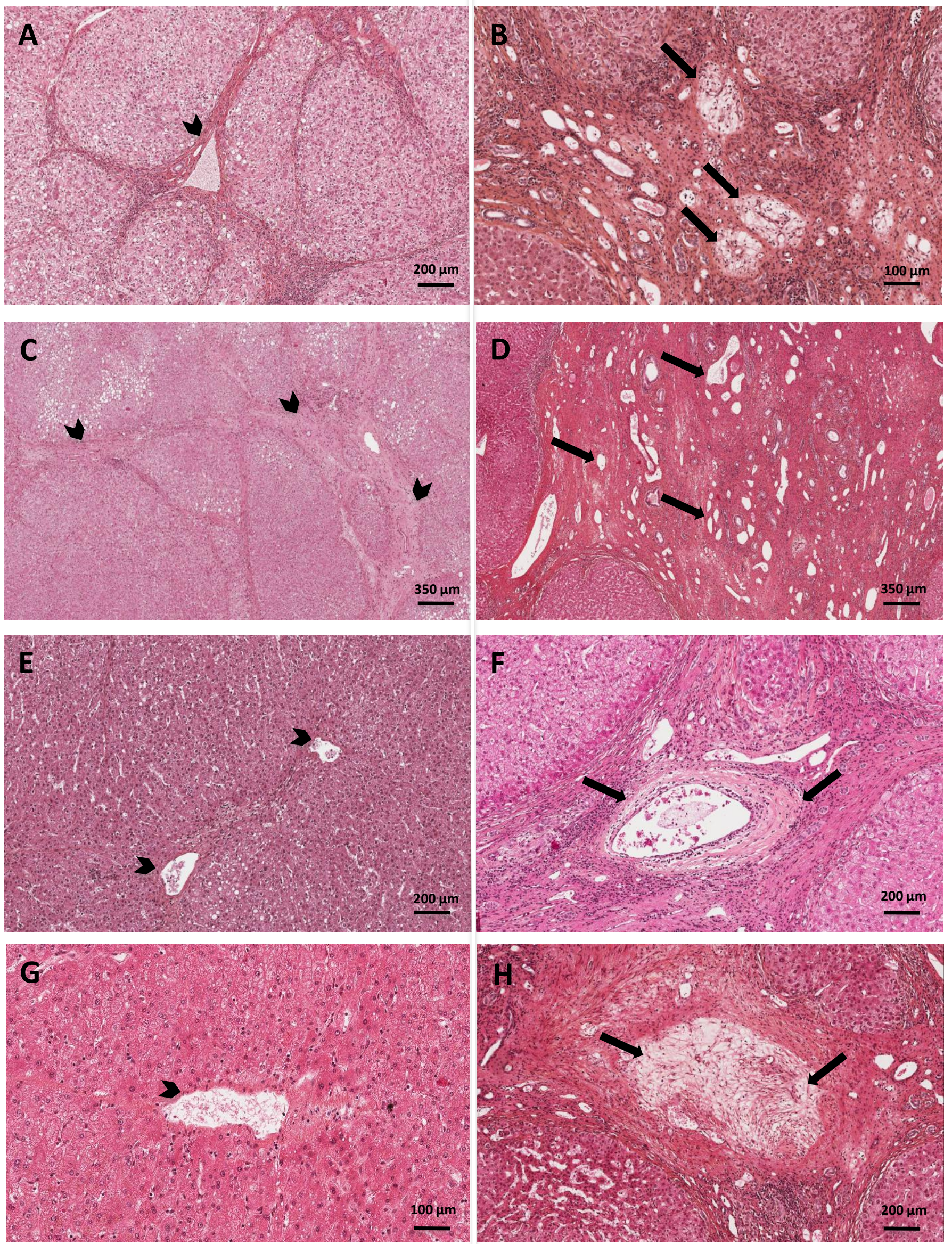


\section{Figure 3}

Control patients
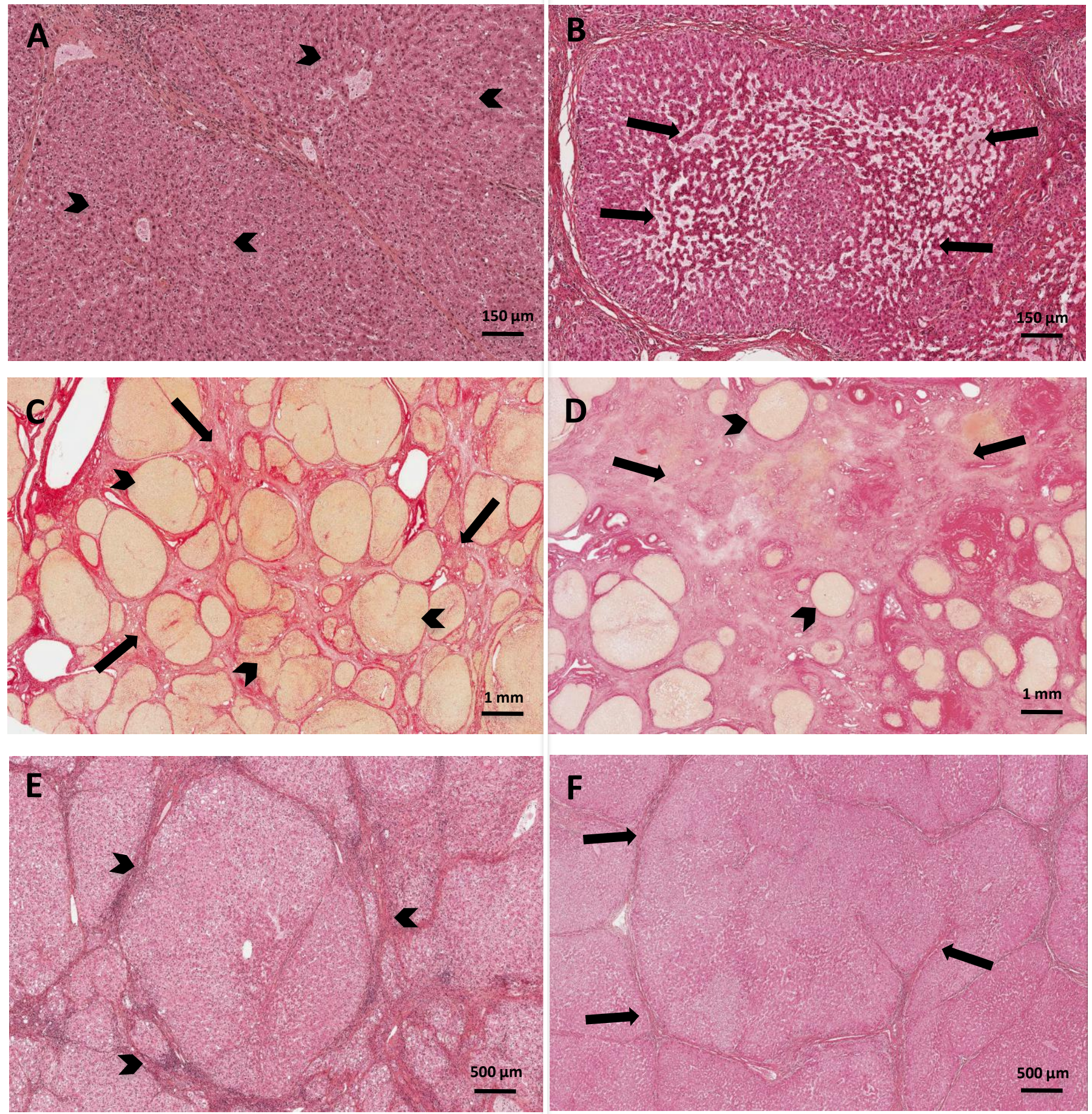

F

\section{HPS patients}

